\section{Expansion and Differentiation in Chinese Higher Education} Jian LiU and Xiaoyan Wang

Jian Liu is a PhD candidate at the Ontario Institute for Studies in Education, University of Toronto. E-mail: jian99.liu@utoronto.ca. Xiaoyan Wang is a research fellow at City University of Hong Kong. E-mail: xiaoyanzi.wang@utoronto.ca.

$\mathbf{T}^{\mathrm{n}}$ the past decade, China has witnessed unprecedented high1 er education expansion. The gross-enrollment rate jumped from 9.8 percent in 1998 to 23.3 percent in 2008 . At the end of 2008, 29.07 million students were enrolled in tertiary institutions, making China's higher education system the largest in the world. Although a myriad of research studies have concentrated on this grand expansion, few empirical studies have examined the profound changes the system is experiencing. In this article the expansion of baccalaureate and short-cycle programs at local and national institutions is described, in both the public and private sectors and in different disciplines. These trends provide implications for the differentiation of higher education in China.

Higher education in China is composed of formal programs (in regular and adult higher education institutions) and flexible modes (Web-based studies and preparation courses for examinations awarding formal qualifications). This study focuses on regular higher education, because it expanded much faster than adult higher education and flexible modes of higher learning and accommodated 70 percent of the total enrollment in 2008 .

Who Are the Providers of the Expanded Opportunities? Statistics from the Ministry of Education reveal that expansion took place mostly in local higher education institutions (at provincial, prefectural, and municipal levels) rather than national universities, under the jurisdiction of ministries of the central government.

In I998, the enrollment in local colleges and universities was 2.258 million; in 2008 it increased to $\mathrm{I} 4.578$ million. By contrast, the enrollment in national universities only increased from I.54I million in 1998 to I.705 million in 2008. These trends can be partly attributed to the implementation of jurisdiction transfer at the end of the I990s, whereby 250 of a total of 367 colleges and universities under the jurisdiction of ministries of the central government were transferred to provincial jurisdiction.

The relatively "flat" structure of the higher education system became more vertically differentiated during the expansion. Most two-year programs in national universities were closed, resulting in an overall enrollment drop from 206,858 in 1998 to 64,995 in 2008 . By contrast, short-cycle programs flourished in local institutions. The enrollment in two-year programs increased from 997,854 to $7,404,422$, and accounted for more than half of the total enrollment in local public institutions in 2008.

At the same time, the prestige and capacity of national universities were further strengthened through the implementation of two earmarked projects: the 2 II and 985 projects. The 2II project selected Ioo universities for Priority investment beginning in 1993, and the 985 Project was launched to provide even more significant funding to 43 top universities, to raise them to a "world-class" level beginning in May I998. The disparity between national and local institutions has thus significantly widened. The gap in per student expenditure between national and local higher education institutions increased from 3,708 RMB in 1998 to 8,196 RMB in 2006 (a comparable value to that of 1978 ).

The relatively "flat" structure of the higher education system became more vertically differentiated during the expansion.

\section{What Is the Role of the Private Sector?}

After three decades in which private higher education was not allowed, the first minban (people-run) college, a euphemism for private institutions, was established. Nevertheless, private higher education has only begun to flourish with the policy of rapid expansion. In I997, 20 private higher education institutions were providing formal programs, with an enrollment of I4,, 00 students-about 0.9 percent of all regular higher education institutions and 0.4 percent of total enrollments. Under the law for promoting minban education, which was passed in 2003 , the number of private higher education institutions providing formal programs rapidly increased to 638 in 2008, about 28.2 percent of the nation's total.

An interesting phenomenon is the development of secondtier independent colleges - colleges affiliated with public universities, but receiving little public funding, and wholly dependent on student fees. Student intake is at a lower academic level than at the public universities, but the affiliated public universities are expected to assure basic academic quality at these independent colleges. This experiment has caused lively debate over issues such as differential credentials, quality, and equity. There were 322 such independent colleges in 2008. Private institutions and independent colleges together enrolled 3.927 million students, accounting for I9.4 percent of the total enrollment in regular higher education in 2008.

\section{Not Elite Anymore?}

Although four-year baccalaureate programs still host more than half of the total enrollment after the expansion, two-year 
short-cycle programs have grown much faster. In I998, total enrollment was 3.409 million in regular higher education, with 2.235 million (65.6 percent) registered in four-year programs and I.I74 million in two-year programs. By 2008 , fouryear programs accommodated II.422 million students (5.I times the number in 1998) and accounted for 54.6 percent of the total; two-year programs had 9.168 million students (7.8 times the number in 1998).

\section{Which Disciplines Have Expanded Faster?}

Although all programs have enlarged their enrollment capacity through the massification process, significant disparities exist among disciplines in terms of the rate of expansion. Engineering programs have continued to host the largest percentage of the student body, with their share maintained at 40 percent in 2008, while the share of sciences and agriculture has nearly shrunk in half. Enrollment in economics went through a huge increase with the rapid expansion of management and administration programs, from 14.9 percent of total enrollment in 1998 to 24.7 percent in 2008 . The share of education and literature each has increased slightly, while the share of law and social sciences has dropped slightly.

\section{An interesting phenomenon is the development of} second-tier independent colleges-colleges affiliated with public universities, but receiving little public funding, and wholly dependent on student fees.

Thus, enrollment in four-year programs no longer exceeds the numbers in two-year programs across all disciplines. As of 2008 , enrollment in short-cycle programs in the three disciplines of education, engineering, and management and administration exceeded the four-year programs. Agriculture and medicine programs also gained a much higher proportion of two-year enrollments than was the case in r998. However, the dominance of four-year science programs was strengthened over the same period, with their enrollments being 236.I times greater than those of two-year programs in 2008 .

\section{CONCLUSION}

The expansion and reconstruction of the Chinese higher education system over the last decade has resulted in increased decentralization, differentiation, and privatization of the system. Chinese higher education has evolved into a hierarchical and diversified system: national universities remain at the top, ambitiously focused on attaining "world-class" status and promoting national competitiveness and prestige; local public universities remain in the middle, acting as the major providers for higher education and contributing to local development; and private institutions are largely at the bottom, focusing on vocational programs. However, a significant outcome of this massification process is that through the differentiated expansion of four- and two-year programs, particularly along disciplinary lines, the diversity of higher education provision has been greatly enhanced. This result could be attributed to the insufficient resources mobilized for the expansion. However, the process of differentiation has practically diversified the curricula structure, making it more responsive to the requirements of social and economic development in the country.

\section{Postcompulsory Education and Training in China \\ QI WANG}

Qi Wang is a lecturer at the Graduate School of Education, Shanghai Jiao Tong University.E-mail: qimwang@sjtu.edu.cn.

The recent debate on building a learning society in China 1 has focused on the gap between individuals' learning motivation and the government's policy orientation on further developing postcompulsory [i.e., postsecondary] education and training programs through certified learning. This gap, reflecting China's cultural and historical force of credentialism, is believed to be a barrier to the promotion of lifelong learning.

\section{Govern ment Perspective}

Since the late I990s, the Chinese government at both national and municipal levels has strongly advocated to build a "learning society" in government policies, such as the 2003-2007 Action Plan for Invigorating Education in 2004, the Action Plan for the Nation's Science Literacy in 2006, and the IIth Five-Year Plan for Education in 2007. Other policies emphasizing the development of a lifelong-learning culture have been enacted through direct educational initiatives and regulations, such as the employment promotion law of the People's Republic of China, the decision on promoting vocational education, and the construction of a vocational qualification system. The development of these policies reflects the key national initiative to revitalize the nation based on science, education, and skill development.

In response to these policy initiatives, a large number of new certified education and training programs have sprung up in the postcompulsory sector in China, in addition to university education and degrees. Such certified programs include accounting, law, manufacturing, environmental sciences, and almost all culminate with a professional qualification exam. These programs are designed and implemented mainly by the relevant industries and the government at different levels, as 